\title{
Effect of a Purse-String Approximation Following Stoma Takedown on Wound Infection and Satisfaction
}

\author{
In Ja Park \\ Department of Colon and Rectal Surgery, Asan Medical Center, University of Ulsan College of Medicine, Seoul, Korea
}

See Article on Page 29-33

A temporary stoma is commonly used following rectal cancer surgery because a stoma has been reported to lower the clinical leak rate and the reoperation rate [1]. The use of a temporary stoma has been increasing due to the introduction and increased use of preoperative chemoradiotherapy (PCRT) in the era of rectal cancer surgery because PCRT was expected to facilitate sphincter preservation in patients with low-lying rectal cancer $[2,3]$. Morbidity after stoma takedown, however, is not negligible, and surgical site infection (SSI) is a very common complication; its incidence which varies widely and has been reported to be as high as $40 \%[4,5]$. Although various methods have been employed to reduce the SSI rate, which technique for closure of a stoma would be the most effective in reducing the SSI rate is still being debated. The pursestring stoma closure described by Banerjee [6] was based on the concept of leaving the wound open to provide drainage and minimize SSI while providing some degree of wound approximation to minimize the healing time. From a morphological viewpoint, an elliptical or circular incision should be closed in a linear fashion for the primary ileostomy takedown wound, so it looked unnatural and the wound was usually larger than the stoma opening made by using an elliptical incision. Recently, a number of studies have reported that the purse-string closure technique resulted in a lower SSI rate than conventional primary closure $[7,8]$.

The authors of "Clinical trial on the incidence of wound infection and patient satisfaction after stoma closure: Comparison of two skin closure techniques" comparing purse-string with primary

Correspondence to: In Ja Park, M.D.

Department of Colon and Rectal Surgery, Asan Medical Center, University of Ulsan College of Medicine, 88 Olympic-ro 43-gil, Songpa-gu, Seoul 138-736, Korea

Tel: +82-2-3010-3937, Fax: +82-2-474-6701

E-mail: ipark@amc.seoul.kr

(C) 2015 The Korean Society of Coloproctology

This is an open-access article distributed under the terms of the Creative Commons Attribution NonCommercial License (http://creativecommons.org/licenses/by-nc/3.0) which permits unrestricted noncommercial use, distribution, and reproduction in any medium, provided the original work is properly cited. closure for ileostomy wounds demonstrated a lower incidence of SSI and a higher patient satisfaction when ileostomy wounds were closed using the purse-string method [9]. Although the study was a retrospective one, the patient populations in the two arms of the trial were well matched in most respects such as indications, types of stoma, and times to stoma closure. However, because the followup time was not long, at best, the study shows a short-term benefit. Regarding patients satisfaction based on a cosmetic viewpoint, that satisfaction might be improved after a longer follow-up because scar shrinkage would have progressed further. In this regard, most studies have shown a more contracted wound at a 1-year followup and, thus, and an improved patient satisfaction $[7,8]$.

The purse-string closure method has been criticized because of the time required for wound healing. However, the wound healing time following purse-string closure has been reported to be shorter than that following primary closure $[5,7]$, which is the same as the results reported by the authors of "Clinical trial on the incidence of wound infection and patient satisfaction after stoma closure: Comparison of two skin closure techniques" [9]. The way in which an open wound affects the quality of life of a patient needs to be investigated further because a higher infection rates is also associated with patient dissatisfaction. With the purse-string closure procedure, the wound must be kept clean at home; however, the patient does not need to go to the hospital to receive any special treatment.

\section{CONFLICT OF INTEREST}

No potential conflict of interest relevant to this article was reported.

\section{REFERENCES}

1. Tan WS, Tang CL, Shi L, Eu KW. Meta-analysis of defunctioning stomas in low anterior resection for rectal cancer. Br J Surg 2009; 96:462-72.

2. Crane CH, Skibber JM, Birnbaum EH, Feig BW, Singh AK, Delclos ME, et al. The addition of continuous infusion 5-FU to preoperative radiation therapy increases tumor response, leading to increased sphincter preservation in locally advanced rectal can- 
cer. Int J Radiat Oncol Biol Phys 2003;57:84-9.

3. Sauer R, Becker H, Hohenberger W, Rodel C, Wittekind C, Fietkau R, et al. Preoperative versus postoperative chemoradiotherapy for rectal cancer. N Engl J Med 2004;351:1731-40.

4. Hackam DJ, Rotstein OD. Stoma closure and wound infection: an evaluation of risk factors. Can J Surg 1995;38:144-8.

5. Sutton CD, Williams N, Marshall LJ, Lloyd G, Thomas WM. A technique for wound closure that minimizes sepsis after stoma closure. ANZ J Surg 2002;72:766-7.

6. Banerjee A. Pursestring skin closure after stoma reversal. Dis Colon Rectum 1997;40:993-4.

7. Reid K, Pockney P, Pollitt T, Draganic B, Smith SR. Randomized clinical trial of short-term outcomes following purse-string versus conventional closure of ileostomy wounds. Br J Surg 2010;97: 1511-7.

8. Camacho-Mauries D, Rodriguez-Diaz JL, Salgado-Nesme N, Gonzalez QH, Vergara-Fernandez O. Randomized clinical trial of intestinal ostomy takedown comparing pursestring wound closure vs conventional closure to eliminate the risk of wound infection. Dis Colon Rectum 2013;56:205-11.

9. Yoon SI, Bae SM, Namgung H, Park DG. Clinical trial on the incidence of wound infection and patient satisfaction after stoma closure: comparison of two skin closure techniques. Ann Coloproctol 2015;31:29-33. 